\title{
Acute kidney injury and its outcome in obstetrics
}

\author{
Dipal C. Shah ${ }^{1 *}$, Babulal S. Patel ${ }^{1}$, Akshay C. Shah ${ }^{1}$, Shashwat K. Jani ${ }^{1}$, Saumya P. Agrawal ${ }^{1}$, \\ Vismay B. Patel ${ }^{2}$, Adwait B. Patel ${ }^{1}$
}

\begin{abstract}
${ }^{1}$ Department of Obstetrics and Gynecology, Smt. NHL Municipal Medical College, SVPIMSR, Ahmedabad, Gujarat, India

${ }^{2}$ Department of Obstetrics and Gynecology, GCS Medical College, Hospital and Research Centre, Ahmedabad, Gujarat, India
\end{abstract}

Received: 27 March 2020

Accepted: 29 April 2020

\author{
*Correspondence: \\ Dr. Dipal C. Shah, \\ E-mail: dipal1995diva@gmail.com
}

Copyright: () the author(s), publisher and licensee Medip Academy. This is an open-access article distributed under the terms of the Creative Commons Attribution Non-Commercial License, which permits unrestricted non-commercial use, distribution, and reproduction in any medium, provided the original work is properly cited.

\section{ABSTRACT}

Background: Acute kidney injury occurring during pregnancy, labour, delivery, and/or postpartum period. Proper management of AKI (acute kidney injury) is challenging because (i) both maternal and fetal health must be considered and (ii) the cardiovascular and renal adaptations of pregnancy add to the complexity for management.

Methods: The objective of this study was to study association and contributing factors in AKI, a retrospective study of 20 cases of AKI complicating pregnancies carried out in department of obstetrics and gynecology, SVPIMSR over a period of 12 months and results were studied and analysed. Etiological factors, associated liver pathology, coagulation abnormality, thrombocytopenia, sepsis, recovery status and fetomaternal outcome were studied and tabulated. AKI was analysed in terms of maximal stage of renal injury attained as per risk, injury, failure, loss of function, and end-stage renal disease (RIFLE) criteria.

Results: The incidence of ARF (acute renal failure) in pregnancy was about $0.3 \%$. Hypertensive disorders were the major causative factor. Amongst the 20 cases, 8 cases were referred from outside and two of them died. Total 5 of 20 cases required hemodialysis and two of them had partial recovery.

Conclusions: AKI complicating pregnancies are not uncommon. If recognized and treated promptly, recovery is assured in majority of cases. Early identification and prompt management of pre-eclampsia and sepsis can prevent majority of cases. Ultrasonography revelation of placenta previa or abruption helps in early management eventually decreases the chances of bleeding which is one of the causes of AKI (pre-renal cause).

Keywords: Feto maternal outcome, Hemodialysis, Hypertension, Kidney injury, Pregnancy

\section{INTRODUCTION}

Acute kidney injury is a syndrome characterized by the rapid loss of kidney's excretory function and is typically diagnosed by accumulation of end products of nitrogen metabolism (urea and creatinine) in serum or reduced urine output or both. The renal changes may last temporarily, and resolve within a few weeks postpartum, or may become irreversible leading to a progression of chronic kidney disease (CKD). ${ }^{1,2}$ Raising the values of serum creatinine by $0.3 \mathrm{mg} / \mathrm{dl}(26.5 \mu \mathrm{mol} / \mathrm{l})$ within 48 hours or increase in serum creatinine to 1.5 times baseline, which is known or presumed to have occurred within the prior 7 days; or urine volume of $<0.5 \mathrm{ml} / \mathrm{kg} /$ hour for 6 hours. $^{3}$ Pre-eclampsia/eclampsia is the most common cause of AKI during antepartum and postpartum period, however, the outcome and prognosis of pre-eclampsia related AKI is good. Amniotic fluid embolism and postpartum haemorrhage, HELLP syndrome (haemolysis, elevated liver enzymes, low platelets) are the leading causes of maternal mortality in AKI patients. ${ }^{4,5}$ The incidence of AKI in pregnancy declined significantly over the years in western world countries but is still a significant cause of maternal morbidity and mortality in developing countries. 
It currently affects 1 per 20,000 pregnancies developed countries. $^{6,7}$ Where as in India incidence of pregnancy related acute kidney injury is $3.7 \%$ in 2000 's. ${ }^{8,9}$ Mortality in mothers due to pregnancy related AKI is $6.4 \% .{ }^{10}$ Hence it is important to focus on the prevention, early diagnosis and identification of high-risk factors in pregnant women and improvement in the care during the peripartum period to improve maternal and perinatal outcomes. It has been seen that majority of the AKI case are preceded by Hypertensive disorders of pregnancy. ${ }^{11}$

Due to advances in contraception, legalizing abortion and more careful monitoring of the perinatal period, the incidence of AKI is on decreasing trend. ${ }^{9,12,13}$

With early diagnosis and prompt management AKI during pregnancy and postpartum period high rates of recovery is observed.

The maternal condition after active treatment was good, whereas the pregnancy outcomes were generally poor. ${ }^{14,15}$

\section{METHODS}

Retrospective observational study conducted in the department of obstetrics and gynecology, Smt NHL Municipal Medical College, SVPIMSR, Ahmedabad, Gujarat, India from February 2019 to January 2020. Total 20 cases were studied and analysed.

Data collected from cases were analysed, computed and tabulated.

\section{Inclusion criteria}

- Anuria

- $\quad$ Sudden oliguria (24-hour urine output $<400 \mathrm{ml}$ )

- Serum creatinine $>1.5 \mathrm{mg} / \mathrm{dl}$

- $\quad$ Rise in serum creatinine $>0.3 \mathrm{mg} / \mathrm{dl}$ within 2 days.

\section{Exclusion criteria}

- Already known cases of chronic kidney diseases

- Past history of dialysis or AKI in previous pregnancy.

The etiological factors like associated liver pathology, coagulation abnormality, thrombocytopenia, sepsis, and recovery status and fetomaternal outcome were studied and results were tabulated.

\section{RESULTS}

In present study, total 20 patients were studied. As shown in Table 1, pregnancy related acute kidney injury was most common in patients with hypertension related disorders like pre-eclampsia (45\%) eclampsia $(5 \%)$ and HELLP syndrome $(10 \%)$. Collectively about $60 \%$ of pregnancy associated AKI cases were due to hypertension related complications in pregnancy. Second most common is septicaemia accounting for about $20 \%$ of cases.
Table 1: Etiological factors of pregnancy related AKI in present study.

\begin{tabular}{|lll|}
\hline Etiological factor & $\begin{array}{l}\text { Number of } \\
\text { cases=20 }\end{array}$ & Percentage \\
\hline Preeclampsia & 9 & $45 \%$ \\
\hline Eclampsia & 1 & $5 \%$ \\
\hline HELLP syndrome & 2 & $10 \%$ \\
\hline Septicaemia & 4 & $20 \%$ \\
\hline Antepartum haemorrhage & 2 & $10 \%$ \\
\hline Postpartum haemorrhage & 2 & $10 \%$ \\
\hline
\end{tabular}

As described in Table 2, pregnancy related acute kidney injury was more common in patients with age $>30$ years as chances of hypertension related complications increase with increasing maternal age and pregnancy related hypertensive disorders being the commonest etiological factor of AKI. Also, it has been observed that, aged women are multipara, which is itself an independent cause of AKI in pregnancy.

Table 2: Association between maternal age and acute kidney injury.

\begin{tabular}{|lll|}
\hline Age & Number of cases=20 & Percentage \\
\hline$<30$ years & 7 & $33.3 \%$ \\
\hline$>30$ years & 13 & $66.7 \%$ \\
\hline
\end{tabular}

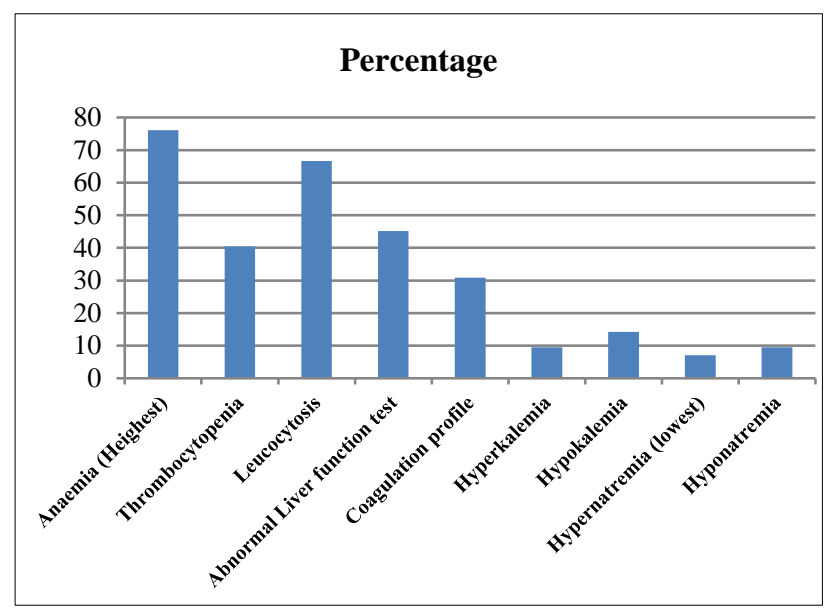

Figure 1: Association between AKI and laboratory investigations.

As shown in Figure 1, with renal function tests, other organ functions are also affected. Anaemia, leukocytosis (which suggests septicaemia) and abnormal liver function test (suggests multi system involvement) were present in about two-third of cases.

Hypertension related complications are frequently associated with abnormal liver function tests and leukocytosis a common laboratory abnormality in these patients. Serum electrolytes levels alterations are also noted which suggests metabolic functional damage in kidney. 
Results mentioned in Table 3 show that, complete renal recovery was seen in $17(85 \%)$ cases, partial recovery in 1 $(5 \%)$ cases and maternal death occurred in $2(10 \%)$ cases. Those 2 cases of maternal death were referred cases of vaginal deliveries with PPH from outside. Admission to death interval was 1 to 10 hours in these cases of maternal death.

Table 3: Outcome followed by management in acute kidney injury cases.

\begin{tabular}{|lll|}
\hline Outcome & $\mathbf{N}=\mathbf{2 0}$ & Percentage \\
\hline Complete recovery & 17 & $85 \%$ \\
\hline Death & 2 & $10 \%$ \\
\hline Partial recovery & 1 & $5 \%$ \\
\hline
\end{tabular}

Table 4: Fetomaternal outcome in acute kidney injury case.

\begin{tabular}{|llll|}
\hline \multirow{3}{*}{ Maternal } & Outcome & N=20 & Percentage \\
\cline { 2 - 4 } & Recovery & 18 & $90 \%$ \\
\cline { 2 - 4 } Fetal & Death & 2 & $10 \%$ \\
\cline { 2 - 4 } & Still birth/IUD & 6 & $30 \%$ \\
\cline { 2 - 4 } & Live & 14 & $70 \%$ \\
\hline
\end{tabular}

Table 4 shows that, $90 \%$ of cases had recovery and maternal death occurred in 2 cases. AKI was associated with poor fetal outcome. Only 14 out of 20 had live birth, rest 1 was stillbirth and 5 were intrauterine death.

Incidence of pregnancy related AKI has reduced in developed countries but is still an important cause of maternal and perinatal morbidity and mortality in developing countries. Hypertensive disorders of pregnancy (pre-eclampsia, eclampsia and HELLP syndrome) are the commonest causes of acute kidney injury.

Though maternal outcomes are good, intensive management and ICU care with teamwork of obstetricians and neonatologist along with physicians and nephrologists is required for better recovery of patients. AKI due to hypertensive disorders usually have good prognosis. AKI due to haemorrhage and septicaemia, in spite of intensive management do not recover fully and they may develop chronic kidney diseases.

\section{DISCUSSION}

AKI is less often but prognosis is unpredictable. About $30 \%$ cases of total ARF are due to pregnancy complication, worldwide incidence of pregnancy-related acute kidney injury has decreased in are developed countries because of the government schemes of nutritional supports to adolescent girls, legal abortions and improvement of antenatal and obstetriccare. ${ }^{16}$ In the recent years; the incidence of pregnancy related AKI in developed countries is only 1 to $2.8 \%$.
However, pregnancy related AKI is still frequent in developing countries and the incidence is around 4.2$15 \% .{ }^{17}$ Due to lack of awareness in mothers, home deliveries, multiparity, poor pre pregnant nutritional status and other factors. It has been seen that incidence of AKI is more common in postpartum period rather than postabortal period. Hypertension and its related complications are the leading cause of AKI in present study followed by septicemia. Incidence is more in females of age $>30$ years of age. This is due to increased risk of hypertensive complications with increasing age. Though maternal outcome is good if early diagnosis and prompt management is done but neonatal outcome is usually poor in pregnancies associated with acute kidney injury, due to poor placental function in mother with preeclampsia and maternal septicemia, which causes fetal growth insult.

It has been seen that if this patients are properly managed in the antenatal period, authors can decrease the development of kidney injury in these patients. ${ }^{10}$ Also, it has been seen in Patients with AKI during their management that not only renal enzymes are altered, anaemia, thrombocytopenia, leukocytosis are also noted, which is suggestive of multi organ insult. Prevention, early diagnosis and early treatment are ideal. Avoiding nephrotoxic drugs, ensuring volume status/perfusion pressure, periodic blood pressure monitoring, and monitoring of serum creatinine and urine output are essential. $^{18}$

The role of steroids in HELLP syndrome is debatable as steroid therapy does not have effect on length of hospitalization, speed of recovery and development of complications. ${ }^{19}$

With proper management of acute kidney injury, mortality rate is in decreasing trend nowadays.

\section{CONCLUSION}

AKI if recognized and managed timely, recovery is in majority of cases $(85 \%)$. Early identification and prompt management of pre-eclampsia and septicaemia can prevent majority of AKI cases. Prolonged duration of oliguria, persistent rise of serum creatinine in spite of proper management and antepartum haemorrhage during antenatal periods leads to poor renal outcome and irreversible renal failure.

The main line of management requires in these types of cases is prompt delivery of fetus, vigorous volume resuscitation, suitable antibiotics, correction of electrolyte imbalance, and haemodialysis as required, which helps in speedy recovery. Close observation and intervention are required for pregnancy related AKI including obstetrician /ICU /nephrologists /neonatologist reviews. In spite of frequent occurrence of AKI in pregnancy in developing countries, it recovers in majority cases and it is preventable by intensive antenatal care and timely post-partum management. 
Funding: No funding sources

Conflict of interest: None declared

Ethical approval: Not required

\section{REFERENCES}

1. Filipowicz E, Staszków M. Pregnancy-related acute kidney injury. Wiad Lek. 2016;69(5):721-4.

2. Prakash J, Prakash J, Niwas SS, Parekh A, Pandey LK, Sharatchandra L, et al. Acute kidney injury in late pregnancy in developing countries. Renal Failure. 2010;32(3):309-13.

3. Nwoko R, Plecas D, Garovic VD. Acute kidney injury in the pregnant patient. Clin Nephrol. 2014;78:47886.

4. Goplani KR, Shah PR, Gera DN, Gumber M, Dabhi, M, Feroz A, et al. Pregnancy related acute renal failure: a single-center experience. Indian J Nephrol. 2016;18:17-21.

5. ACOG practice bulletin. Diagnosis and management of preeclampsia and eclampsia. Number 33, January 2018. ACOG Commit Pract Bullet Obstet Obstet Gynecol. 2002;99(1):159.

6. Huang C, Chen S. Acute kidney injury during pregnancy and puerperium: a retrospective study in a single center. BMC Nephrol. 2017;18(1):146.

7. Mahajan S, Tiwari S, Bhowmik D, Agarwal SK, Tiwari SC, Dash SC. Factors affecting the outcome of acute renal failure among the elderly population in India: a hospital-based study. Int Urol Nephrol. 2006;38(2):391-6.

8. Kumar KS, Krishna CR, Siva Kumar V. Pregnancy related acute renal failure. Obstet Gynecol India. 2006;56:308-10.

9. Najar MS, Shah AR, Wani IA, Reshi AR, Banday KA, Bhat HA, et al. Pregnancy related acute kidney injury: a single centre experience from the Kashmir valley. Indian J Nephrol. 2008;18:159-61.

10. Prakash J, Kumar H, Sinha DK, Kedalaya PG, Pandey LK, Srivastava PK, et al. Acute renal failure in pregnancy in a developing country: twenty years of experience. Renal Failure. 2006;28(4):309-13.

11. Patel BS, Patel FB, Bhatt MK. Acute renal failure in obstetrics. J Obstet Gynecol India. 2000;50(3):40.

12. Prakash J, Ganiger VC. Acute kidney injury in pregnancy-specific disorders. Indian $\mathrm{J}$ Nephrol. 2017:27(4):258.

13. Prakash J, Pant P, Prakash S, Sivasankar M, Vohra R, Doley PK, et al. Changing picture of acute kidney injury in pregnancy: Study of 259 cases over a period of 33 years. Ind J Nephrol. 2016;26(4):262-7.

14. Liu Y, Bao H, Jiang Z, Huang Y, Wang N. Pregnancyrelated Acute Kidney Injury and a review of the literature in China. Intern Med. 2015;54(14):1695703.

15. Liu YM, Hong DB, Jiang ZZ, Huang YJ, Wang NS. Pregnancy-related acute kidney injury and a review of the literature in China. Internal Med. 2015;54(14):1695-703.

16. Arrayhani M, El Youbi R, Sqalli T. Pregnancy-related acute kidney injury: experience of the nephrology unit at the university hospital of fez, morocco. ISRN Nephrol. 2012;2013.

17. Godara SM, Kute VB, Goplani KR, Gumber MR, Gera DN, Shah PR, et al. Mucormycosis in renal transplant recipients: predictors and outcome. Saudi J Kid Dis Transplant. 2011;22(4):751.

18. Godara SM, Kute VB, Trivedi HL, Vanikar AV, Shah PR, Gumber MR, et al. Clinical profile and outcome of acute kidney injury related to pregnancy in developing countries: a single-center study from India. Saudi J Kid Dis Transplant. 2014;25(4):906.

19. Ganesan C, Maynard SE. Acute kidney injury in pregnancy: the thrombotic microangiopathies. J Nephrol. 2011;24(5):554-63.

Cite this article as: Shah DC, Patel BS, Shah AC, Jani SK, Agrawal SP, Patel VB, et al. Acute kidney injury and its outcome in obstetrics. Int J Reprod Contracept Obstet Gynecol 2020;9:2508-11. 